\title{
Nail Psoriasis in Children: Common or Uncommon? Results from a 10-Year Double-Center Study
}

\author{
Bianca Maria Piraccini ${ }^{a}$ Ioanna Triantafyllopoulou ${ }^{b}$ Christos Prevezas $^{b}$ \\ Michela Starace $^{a} \quad$ Iria Neri $^{\mathrm{a}}$ Annalisa Patrizi $^{\mathrm{a}}$ Maurizio Caserini ${ }^{\mathrm{c}}$ \\ Renata Palmieric Dimitrios Rigopoulos ${ }^{\mathrm{b}}$ \\ ${ }^{a}$ Division of Dermatology, Department of Experimental, Diagnostic and Specialty Medicine, University of Bologna, \\ Bologna, Italy; ${ }^{\text {}}$ Nail Disorders Unit, Second Department of Dermatology, Attikon University Hospital, Athens, \\ Greece; ' Scientific Department, Polichem S.A., Lugano, Switzerland
}

\section{Key Words}

Children · Epidemiological study · Nail psoriasis

\begin{abstract}
Purpose of the Study: Our aim was to perform an extensive search of the literature on the prevalence of nail psoriasis in the pediatric population and to estimate it on our own database. Procedures: Searching the most important databases yielded results of 16 papers published in a 40-year period which reported the prevalence of nail psoriasis in children. Furthermore, data gathered between 2004 and 2013 at two centers specialized in nail disorders were analyzed. Results: The selected papers encompassed a total of 4,853 psoriatic children, of whom 762 (15.7\%) had nail involvement. Concerning our data, a total of 68,839 children were seen in pediatric skin consultation in both clinics over a period of 10 years, $0.11 \%$ of which had nail involvement. The rate of psoriatic children presenting nail alterations was $19.4 \%$ in the Greek and $15.5 \%$ in the Italian patient groups. Conclusions and Message: This is the retrospective study including the largest number of cases of nail psoriasis in the pediatric population. Our data are in line with the incidence estimation of the rest of Europe.

(c) 2015 S. Karger AG, Basel
\end{abstract}

(C) 2015 S. Karger AG, Basel

2296-9195/15/0011-0043\$39.50/0

\section{Introduction}

The lifetime prevalence of psoriasis ranges between 1 and $3 \%$ of the general population [1]. In children, the prevalence of psoriasis is $0.71 \%$ in Europe and is increasing throughout the years [2]. Epidemiological studies reveal that in $37 \%$ of the adult patients, psoriasis appears by the age of 20 , in $27 \%$ by the age of 15 , in $10 \%$ by the age of 10 and in $2 \%$ by the age of 2 [3-5]. An earlier onset heralds a graver prognosis as well as higher familial occurrence [6]. Concerning the variants of clinical psoriasis, the guttate form is the commonest one, followed by the plaque type (fig. 1), whereas erythrodermic and pustular forms seem to be absent [7]. Common sites of involvement are the napkin, scalp, face and nails [8].

Nail lesions are observed in about half of the patients with psoriasis, with an estimated lifetime incidence of 80 $90 \%[2,9,10]$. Nail psoriasis occurs more often in patients with more severe psoriasis, and there is a positive correlation between the severity of nail lesions and the severity of joint and skin symptoms. However, nail abnormalities may be the only manifestation of psoriasis and are also frequently seen in patients with mild disease [11].

\section{KARGER 125}

E-Mail karger@karger.com www.karger.com/sad
Ioanna Triantafyllopoulou, MD

3A Dervenakion Street

GR-15235 Athens (Greece)

E-Mail tiofficial@hotmail.com 


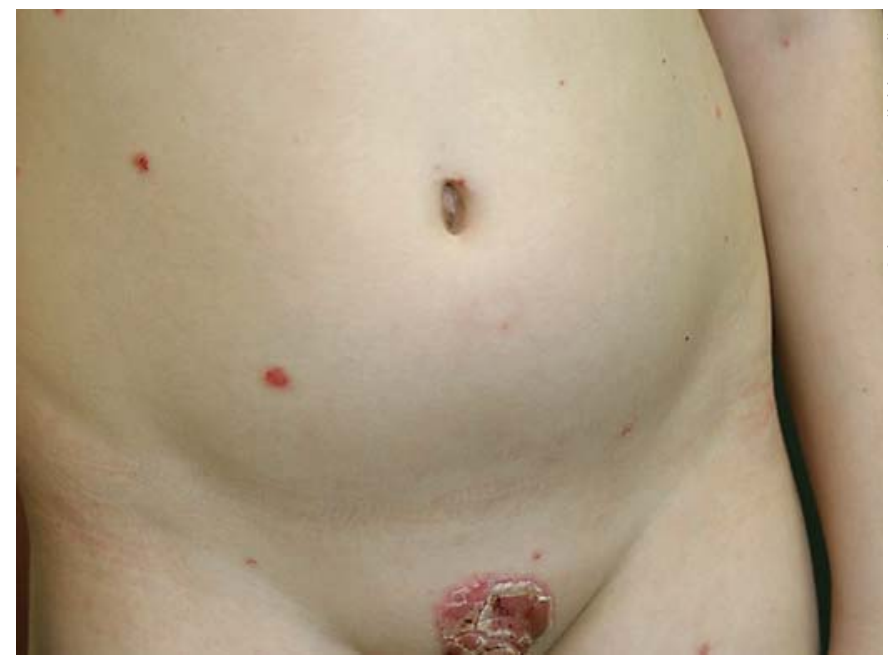

Fig. 1. Plaque type psoriasis in a boy.

Nail psoriasis rarely occurs in children who suffer from skin psoriasis, with an incidence lower than that reported in adults [12]. It is not related to the type of psoriasis or the severity of the disease and is independent of psoriatic arthritis.

Our aim was to estimate the prevalence of nail psoriasis in the pediatric population. We proceeded as follows:

- Performing an extensive search of the literature in the most important databases

- Retrospectively collecting our epidemiological data ranging from 2004 to 2013 concerning the number of children seen in pediatric skin consultation with the diagnosis of psoriasis and, finally, the diagnosis of nail psoriasis

\section{Materials and Methods}

Computerized literature searches on pediatric nail psoriasis using 10 different keywords were conducted through SciFinder, a Chemical Abstracts Service (CAS) database, providing chemical and scientific literature information contained in CA Plus, CAS Registry, CAS React, Chemlist, Chemcat and Medline. Furthermore, the reference lists of published papers/reviews were considered.

A total of 335 papers/reviews up to June 2014 have been retrieved. The mentioned papers have been analyzed in order to select the relevant literature on nail psoriasis prevalence in childhood according to the following rules:

- Some papers were removed as they were retrieved in more than one search
- Papers on psoriatic pediatric patients with a description of nail involvement but in whom the prevalence of nail psoriasis was not reported were excluded

- General reviews were excluded as they were not detailed enough: the reported nail psoriasis prevalence, when available, did not refer to a specific population and had a very large variability

- Case reports were not considered

The search provided evidence of 16 papers published in a 40 year period that reported the prevalence of nail involvement in a defined (age, country, years of observation) psoriatic population at the pediatric age.

Furthermore, data gathered between 2004 and 2013 at two different centers specialized in the diagnosis and treatment of nail disorders were analyzed. The first center (Group GR) is the Nail Disorders Unit, Department of Dermatology, Attikon University Hospital, Athens, Greece, and the second center (Group IT) is the Nail Disorders Unit and Pediatric Dermatology Unit, Division of Dermatology, University of Bologna, Bologna, Italy. The number of children (aged 6-17 years) with nail psoriasis with or without skin involvement was documented each year and compared to the total number of children with nail disorders. The diagnosis relied exclusively on clinical criteria given that in our study population a biopsy was difficult to perform.

\section{Results}

\section{Epidemiological Data from the Literature}

The 16 selected papers encompassed data on a total of 4,853 psoriatic patients at the pediatric age, of whom 762 (15.7\%) had nail involvement (table 1). In all published papers, the average observation period was extremely long, ranging from 1.5 to 30 years. Noteworthy are the huge discrepancies in nail psoriasis rates, ranging from $0.6[13]$ to $79 \%[14]$ of the infants.

The prevalence of pediatric nail psoriasis in Caucasian patients was evaluated by selecting the papers coming from Europe, the US and Australia. A total of 343 pediatric patients out of 3,355 individuals (10.2\%) affected by psoriasis had nail involvement. In the subgroup of European patients, a total of 165 patients $(12.5 \%)$ out of 1,318 children with psoriasis were diagnosed with nail psoriasis. Considering the observation period, the average number of children diagnosed with nail psoriasis was 5.6/year.

\section{Group GR and Group IT Epidemiological Data}

A total of 68,839 children aged 6-17 years were seen in pediatric skin consultation over a period of 10 years at both clinics [30,044 (Group GR) and 38,795 (Group IT)]. The number of patients/year is shown in figure 2. The total number of patients at the pediatric age affected by skin psoriasis was 406 (0.58\%), 284 in Group GR and 122 in Group IT, corresponding to 0.9 and $0.31 \%$ of the pediatric 
Fig. 2. Number of children examined in pediatric skin consultation over a period of 10 years at both clinics.

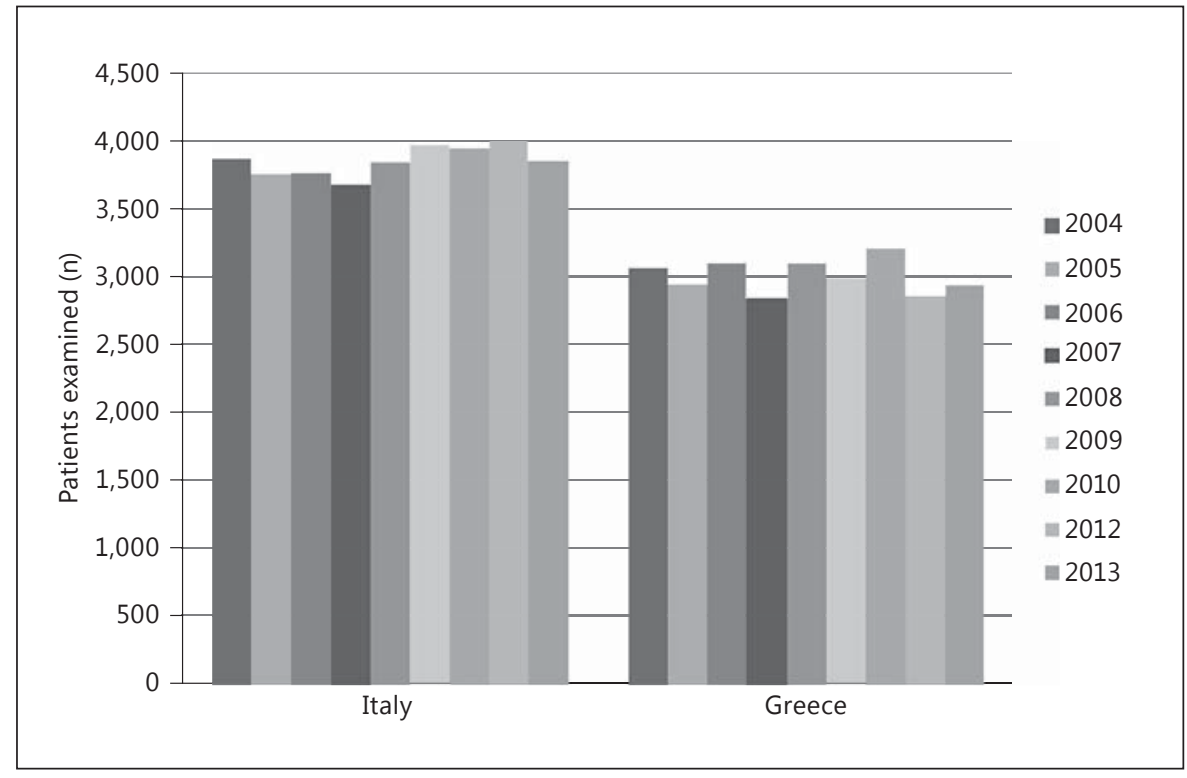

Table 1. Prevalence of nail psoriasis in children based on previously published data

\begin{tabular}{|c|c|c|c|c|c|c|}
\hline Country & Reference (first author) & $\begin{array}{l}\text { Patients } \\
\text { with skin } \\
\text { psoriasis, n }\end{array}$ & $\begin{array}{l}\text { Age at } \\
\text { diagnosis, } \\
\text { years }\end{array}$ & $\begin{array}{l}\text { Patients } \\
\text { with nail } \\
\text { involvement, } \\
\mathrm{n}(\%)\end{array}$ & $\begin{array}{l}\text { Observation } \\
\text { period, } \\
\text { years }\end{array}$ & $\begin{array}{l}\text { Patients/ } \\
\text { year, } \mathrm{n}\end{array}$ \\
\hline Denmark & Nyfors [17], 1975 & 245 & $<16$ & $34(14)$ & NA & NA \\
\hline Greece & Moustou [5], 2014 & 842 & $<18$ & $95(11.8)$ & 20 & 4.75 \\
\hline Turkey & Seyhan [18], 2006 & 61 & $<18$ & $13(21.3)$ & 5 & 2.6 \\
\hline Greece & Stefanaki [8], 2011 & 125 & $<13$ & $13(10.4)$ & 3 & 4 \\
\hline Netherlands & Chiam [16], 2011 & 45 & $<18$ & $10(22.2)$ & 1.5 & 6.5 \\
\hline $\begin{array}{l}\text { Total (Europe) and average o } \\
\text { (years) and patients/year }\end{array}$ & fobservation period & 1,318 & & $165(12.5)$ & 7.4 & 5.6 \\
\hline US & Farber [14], 1977 & 14 & $<2$ & $11(78.6)$ & 12 & 0.9 \\
\hline US & Raychaudhuri [19], 2000 & 223 & $<16$ & $29(13)$ & 14 & 2 \\
\hline Australia & Morris [13], 2001 & 1,262 & $<15$ & $8(0.6)$ & 15 & 0.5 \\
\hline US & Tollefson [1], 2010 & 357 & $<18$ & $59(16.5)$ & 30 & 1 \\
\hline US & Mercy [21], 2013 & 181 & $<17$ & $71(39.2)$ & 2.5 & 28.4 \\
\hline $\begin{array}{l}\text { Total (Caucasians) and avera } \\
\text { (years) and patients/year }\end{array}$ & ge of observation period & 3,355 & & $343(10.2)$ & 11.4 & 3.3 \\
\hline China & Fan [4], 2007 & 277 & $<16$ & $8(5.6)$ & 8 & 1 \\
\hline Kuwait & Al-Mutairi [3], 2007 & 201 & $<16$ & $76(37.8)$ & 2 & 38 \\
\hline Singapore & Chiam [16], 2011 & 162 & $<18$ & $58(35.8)$ & 1.5 & 38.5 \\
\hline China & $\mathrm{Wu}[20], 2010$ & 137 & $<14$ & $35(25.5)$ & 9 & 4 \\
\hline Kuwait & Al-Fouzan [15], 1994 & 190 & $<12$ & $68(36)$ & 1.5 & 34 \\
\hline India & Nanda [6], 1990 & 112 & $<13$ & $44(39.3)$ & 9 & 5 \\
\hline India & Kumar [7], 2004 & 419 & $<14$ & $130(31)$ & 13 & 10 \\
\hline $\begin{array}{l}\text { Total (worldwide) and averą } \\
\text { (years) and patients/year }\end{array}$ & se of observation period & 4,853 & & $762(15.7)$ & 9 & 5.1 \\
\hline
\end{tabular}

Data were divided into three subgroups. The first comprised data on European patients, the second on patients from the US and Australia and the third on patients from the rest of the world. 


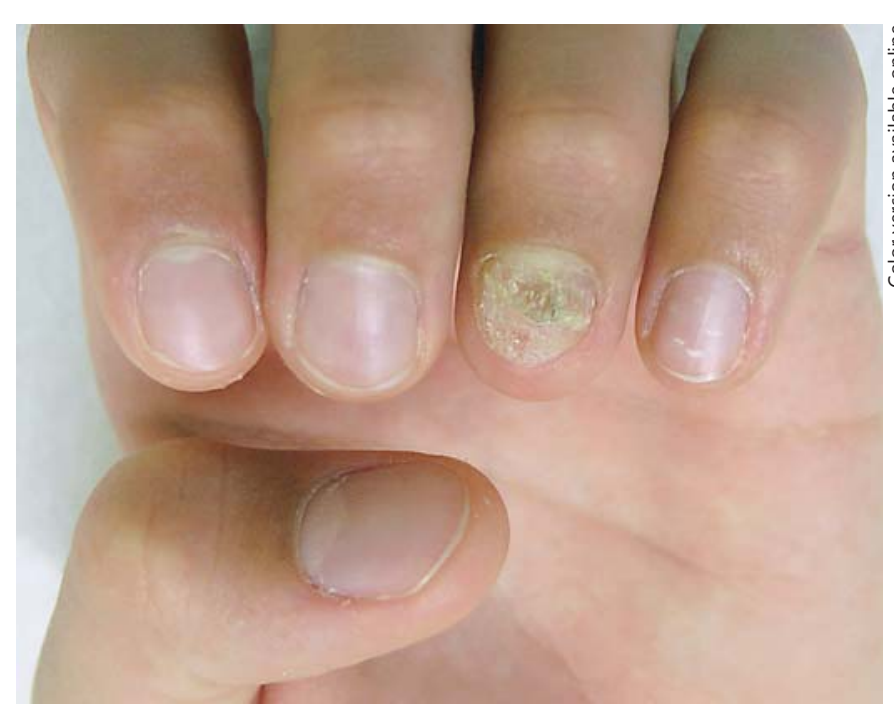

Fig. 3. Onycholysis on the finger of a young girl.

Table 2. Pediatric skin consultations

\begin{tabular}{|c|c|c|c|}
\hline & Group GR & Group IT & Total \\
\hline Total number of children & 30,044 & 38,795 & 68,839 \\
\hline Children with Pso & 284 & 122 & 406 \\
\hline Children with NPso & 55 & 19 & 74 \\
\hline $\begin{array}{l}\text { \% Children with NPso vs. } \\
\text { children with Pso }\end{array}$ & 19.40 & 15.50 & 18.2 \\
\hline $\begin{array}{l}\text { \% Children with NPso vs. } \\
\text { total pediatric population }\end{array}$ & 0.18 & 0.05 & 0.11 \\
\hline
\end{tabular}

Pso $=$ Psoriasis $;$ NPso $=$ nail psoriasis.

population, respectively. Furthermore, a total of 74 out of the 68,839 children $(0.11 \%)$ had involvement of the nails: 55 out of 30,044 in Greece and 19 out of 38,795 in Italy, which equals 0.18 and $0.05 \%$ of all pediatric skin consultations, respectively (table 2 ). With regard to the children with skin psoriasis, the rate of children affected by nail psoriasis was 19.4\% in Group GR and 15.5\% in Group IT.

\section{Discussion}

The severity of nail psoriasis in childhood does not correlate with that of the skin psoriatic lesion. The diagnosis of nail psoriasis could be difficult and the condition could be overestimated as other diseases that induce similar nail signs may be not recognized. These include ony-

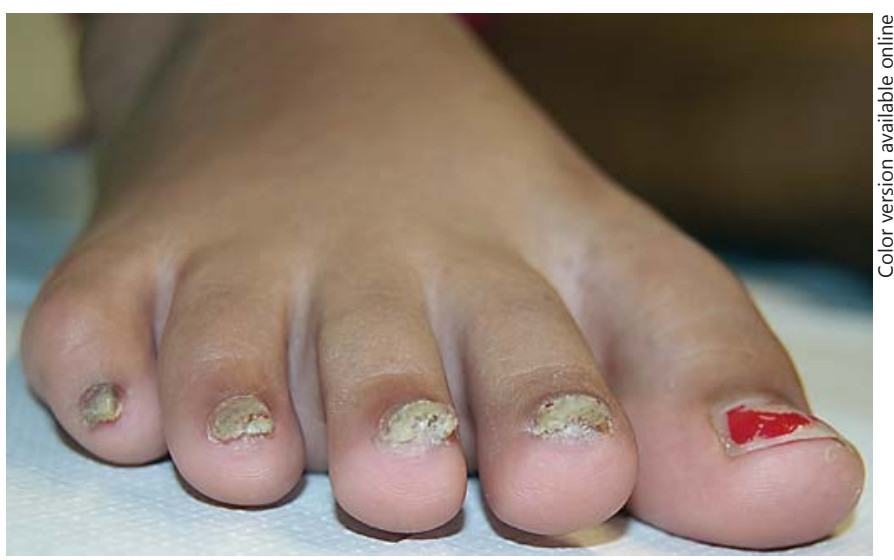

Fig. 4. Subungual hyperkeratosis on the toes of a girl.

chomycosis, trachyonychia, alopecia areata, eczema of the nails and traumatic nail dystrophies. A wide experience of diseases of cutaneous annexes is required to be able to distinguish between the different nail lesions. The most common finding at the two analyzed centers was nail pitting. Pitting was mainly seen in one or more fingernails but rarely in toenails. Furthermore, pitting is not pathognomonic of psoriasis, as it can also be observed in alopecia areata and eczema. Psoriatic pits are typically large and irregular in both shape and distribution. In children, pitting is only rarely associated with other signs of nail psoriasis.

The second common sign of nail psoriasis in children was onycholysis associated with subungual hyperkeratosis (fig. 3, 4). Onycholysis stands for the detachment of the nail plate from the underlying nail bed. The nail plate appears white due to entrapment of air underneath the nail plate. Subungual hyperkeratosis results from excessive proliferation of the nail bed/hyponychium keratinocytes, which leads to the accumulation of scales under the nail plate. Onycholysis and subungual hyperkeratosis are often present in childhood nail psoriasis and may be seen in fingernails but are more evident in toenails. They typically involve several nails, which is an important diagnostic clue. Splinter hemorrhages may be associated, provoked by trauma. The salmon pink erythematous border (oil drop sign), usually surrounding the onycholytic area in psoriasis (fig. 5), may be absent or scarcely visible in children's toenails, making the diagnosis difficult in the absence of other skin features of psoriasis. Since trauma 


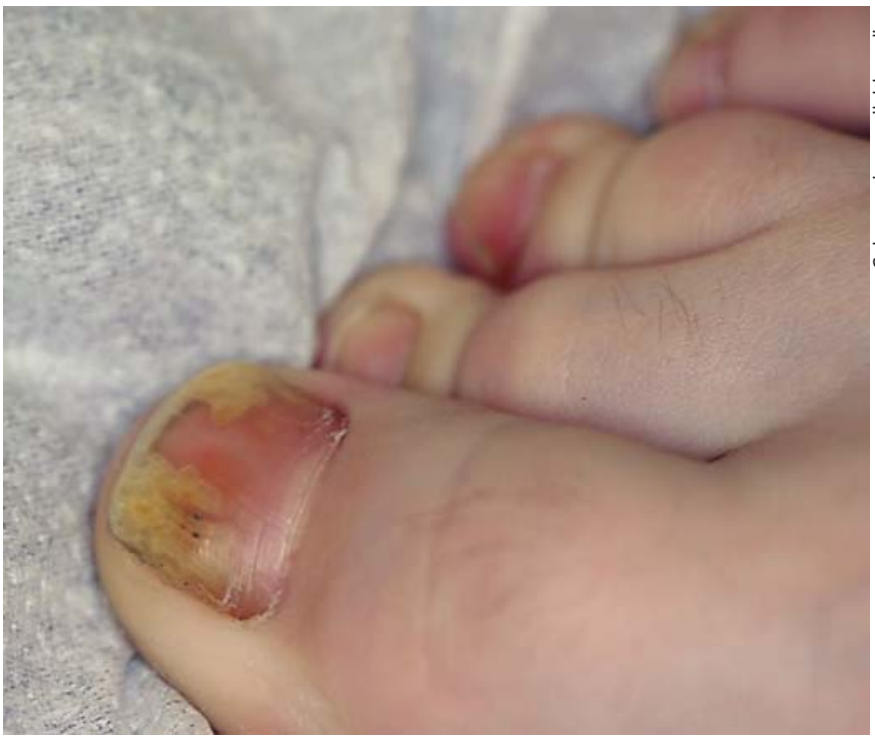

Fig. 5. Oil drop sign on a boy’s big toe.

precipitates nail disease, nail biting provokes onycholysis and subungual hyperkeratosis in fingernails. Differential diagnosis comprises other diseases that cause onycholysis and subungual hyperkeratosis, mainly distal subungual onychomycosis and eczema. Onychomycosis is rare in children, where it can be limited to a single digit. Nail findings may be clinically indistinguishable from those of nail psoriasis, making mycology indispensable. Eczema in childhood is commonly due to atopic dermatitis, which can involve the hand and periungual tissues, causing mild onycholysis and subungual hyperkeratosis. Nail disease is always associated with dermatitis of the dorsal or volar surface of the hand. Nail thickening along with increased transverse curvature due to severe nail bed hyperkeratosis associated with an early onset is a typical finding of pachyonychia congenita. All twenty nails are involved, presenting different degrees of severity. Family history and clinical features lead to a diagnosis.

Nail plate thickening involving several toenails that are difficult to trim is a common sign of presentation of nail psoriasis at a very young age. The parents notice gradual thickening of one or several toenails that are difficult to trim. Differential diagnosis includes onychogryphosis, which is rare in children, especially in those under the age of 10 , and usually involves the first toenail.

Parakeratosis pustulosa was another clinical variant of nail psoriasis we observed. It is usually limited to the thumb or the index finger, presenting mild psoriasis form changes, especially on the side of the nail. In most pa- tients, nail signs were associated with or preceded by erythema, scaling and vesicles of the fingertip. Differential diagnosis includes eczema, and patch tests may reveal allergic contact dermatitis. Parakeratosis pustulosa either regresses spontaneously or evolves into nail psoriasis.

Nail psoriasis may also appear as trachyonychia. Trachyonychia, or twenty-nail dystrophy, is an acquired benign inflammatory disorder of the proximal nail matrix that produces characteristic nail plate surface abnormalities. The affected nail shows a diffuse homogeneous roughness due to fine superficial striations distributed in a regular, longitudinal, parallel pattern. Small, superficial, adherent scales may be present. Nail thinning with koilonychia as well as hyperkeratosis of the cuticles is frequent. Trachyonychia may affect one, several or all nails and is attributed to various inflammatory diseases such as alopecia areata, psoriasis, eczema and lichen planus. In the absence of a detailed history or clinical findings that suggest the underlying disease, it is impossible to identify the cause of trachyonychia without histopathology. However, a nail biopsy is not indicated in trachyonychia, as it is usually a benign condition that tends to improve with time.

The vast majority of papers published, including our own, are based on retrospective studies. The only prospective studies were elaborated in Kuwait [15] and the Netherlands [16].

All studies reporting individual clinical findings of nail psoriasis agree that the most common clinical sign is nail pitting (up to 87\%), which of course is not pathognomonic of the disease. Pitting was indeed the most common sign observed in our series of children with nail psoriasis. Other frequent findings reported in the literature are longitudinal ridging, onycholysis, subungual hyperkeratosis and nail plate discoloration. In our experience, onycholysis with erythematous border, trachyonychia and nail plate crumbling were the other possible presentations of psoriasis in the nails. The only study applying the $\mathrm{KOH}$ examination to rule out fungal infection of the nail was that by Al-Mutairi et al. [3]. In our experience, mycology was necessary only in nail psoriasis limited to the toenails when the symptoms were onycholysis and subungual hyperkeratosis and found in children with psoriasis of a single fingernail with diffuse nail plate crumbling.

The large deviation among the studies concerning the age limit of childhood (ranging from 12 [15] to 18 years [1]) is important for the interpretation of the results. Only one paper referred to infantile psoriasis, the study population being younger than 2. It is now well established that the first peak of age in the occurrence of psoriasis starts 
at the age of 16, thus leading to overestimation of the incidence of nail psoriasis in the studies where children older than 16 years were included. In our study, the age limit was 6-17 years.

Another pitfall of the studies explaining the discrepancies of nail psoriasis rates was that they relied mainly - if not exclusively - on a clinical diagnosis and the fact that such a clinical diagnosis was not made only by dermatologists. Histological confirmation was provided only in doubtful cases, but whether nail biopsies were performed was not specified. In one of the largest studies by Tollefson et al. [1], biopsies were obtained only in $14 \%$ of the psoriasis cases, while in our study as well as in that by AlMutairi et al. [3], focusing solely on nail psoriasis, the diagnosis was exclusively clinical.

Considering the total number of the sample size of our investigation $(68,839)$, this is the retrospective study including the largest number of cases of nail psoriasis in the pediatric population. The prevalence of psoriasis in children aged 6-17 years in pediatric skin consultation was $0.6 \%$ (range $0.9-0.31 \%$ ). Our investigation confirms the European prevalence data, estimated to lie between 1.01 and $0.71 \%$ [2]. From our data, nail psoriasis appears to be rare and sparse. In fact, only $0.11 \%$ (range $0.05-0.18 \%$ ) of the children visiting our center were affected by nail pso- riasis. Practically speaking, 5.5 and 1.9 patients/year were diagnosed in the GR and IT Groups, respectively. These data are in line with the incidence estimation of the rest of Europe (5.6 patients/year/paper).

Our research indicates that the rate of children with nail psoriasis among children with psoriasis (19.4 and $15.5 \%$ for the GR and IT Groups, respectively) is slightly higher in comparison to the European rate published until now (12.5\%). These data reflect that the use of nail disorder units allows an even more accurate diagnosis of nail psoriasis.

In conclusion, we studied a sizeable population of children at two centers specialized in nail disorders for a period long enough to draw the firm conclusion that nail psoriasis in children is a rare condition. In our experience, only $0.11 \%$ of the children visiting us for a dermatological reason and 15.5 (19.4\%) of the children affected by another clinical form of psoriasis have nail involvement.

\section{Disclosure Statement}

The authors have no conflicts of interest to disclose.

\section{References}

1 Tollefson MM, Crowson CS, McEvoy MT, Maradit Kremers H: Incidence of psoriasis in children: a population-based study. J Am Acad Dermatol 2010;62:979-987.

2 Augustin M, Glaeske G, Radtke MA, Christophers E, Reich K, Schafer I: Epidemiology and comorbidity of psoriasis in children. Br J Dermatol 2010;162:633-636.

3 Al-Mutairi N, Manchanda Y, Nour-Eldin O: Nail changes in childhood psoriasis: a study from Kuwait. Pediatr Dermatol 2007;24:7-10.

4 Fan X, Xiao FL, Yang S, Liu JB, Yan KL, Liang YH, Sun LD, Du WH, Jin YT, Zhang XJ: Childhood psoriasis: a study of 277 patients from China. J Eur Acad Dermatol Venereol 2007;21:762-765.

5 Moustou AE, Kakourou T, Masouri S, Alexopoulos A, Sachlas A, Antoniou C: Childhood and adolescent psoriasis in Greece: a retrospective analysis of 842 patients. Int J Dermatol 2014;53:1447-1453.

6 Nanda A, Kaur S, Kaur I, Kumar B: Childhood psoriasis: an epidemiologic survey of 112 patients. Pediatr Dermatol 199;7:19-21.

7 Kumar B, Jain R, Sandhu K, Kaur I, Handa S: Epidemiology of childhood psoriasis: a study of 419 patients from northern India. Int J Dermatol 2004;43:654-658.
8 Stefanaki C, Lagogianni E, Kontochristopoulos G, Verra P, Barkas G, Katsambas A, Katsarou A: Psoriasis in children: a retrospective analysis. J Eur Acad Dermatol Venereol 2011; 25:417-421.

9 Jiaravuthisan MM, Sasseville D, Vender RB, et al: Psoriasis of the nail: anatomy, pathology, clinical presentation, and a review of the literature on therapy. J Am Acad Dermatol 2007; 57:1-27.

10 De Berker D: Management of psoriatic nail disease. Semin Cutan Med Surg 2009;28:3943.

11 Reich K: Approach to managing patients with nail psoriasis. J Eur Acad Dermatol Venereol 2009;23(suppl 1):15-21.

12 Piraccini BM, Starace M: Nail disorders in infants and children. Curr Opin Pediatr 2014; 26:440-445.

13 Morris A, Rogers M, Fischer G, Williams K: Childhood psoriasis: a clinical review of 1262 cases. Pediatr Dermatol 2001;18:188-198.

14 Farber EM, Jacobs AH: Infantile psoriasis. Am J Dis Child 1977;131:1266-1269.

15 Al-Fouzan AS, Nanda A: A survey of childhood psoriasis in Kuwait. Pediatr Dermatol 1994;11:116-119.
16 Chiam LY, de Jager ME, Giam YC, de Jong EM, van de Kerkhof PC, Seyger MM: Juvenile psoriasis in European and Asian children: similarities and differences. Br J Dermatol 2011;164:1101-1103.

17 Nyfors A, Lemholt K: Psoriasis in children. A short review and a survey of 245 cases. Br J Dermatol 1975;92:437-442.

18 Seyhan M, Coşkun BK, Sağlam H, Ozcan H, Karincaoğlu Y: Psoriasis in childhood and adolescence: evaluation of demographic and clinical features. Pediatr Int 2006;48:525530.

19 Raychaudhuri SP, Gross J: A comparative study of pediatric onset psoriasis with adult onset psoriasis. Pediatr Dermatol 2000;17: 174-178.

$20 \mathrm{Wu}$ Y, Lin Y, Liu HJ, Huang CZ, Feng AP, Li JW: Childhood psoriasis: a study of 137 cases from central China. World J Pediatr 2010;6: 260-264.

21 Mercy K, Kwasny M, Cordoro KM, Menter A, Tom WL, Korman N, Belazarian L, Armstrong AW, Levy ML, Paller AS: Clinical manifestations of pediatric psoriasis: results of a multicenter study in the United States. Pediatr Dermatol 2013;30:424-428. 